\title{
HEAVY METAL CONCENTRATION IN SELECTED RIVER TRIBUTARIES IN AN URBAN SETTLEMENT IN AKURE, NIGERIA
}

\author{
Ochuko Mary Ojo \\ Department of Civil and Environmental Engineering, Federal University of Technology, \\ Akure, Ondo State, Nigeria
}

\begin{abstract}
Heavy metals can impact human health and continuous exposure to heavy metals in water can lead to a variety of health issues. Water from surface water bodies such as streams and rivers help to alleviate the problem of water scarcity especially in developing countries. In this study, the heavy metal content of stream water samples was analyzed. Four (4) heavy metals namely Iron ( $\mathrm{Fe}$ ), Chromium ( $\mathrm{Cr}$ ), Cadmium ( $\mathrm{Cd}$ ) and Manganese (Mn) were analyzed in the laboratory and the results obtained were compared with World Health Organization (WHO) standard for potable water. The results revealed that none of the water samples analyzed met WHO standard for Cr in potable water while only $40 \%$ of the water samples analyzed conformed to WHO standard for Cd in potable water. Findings of this study revealed that $\mathrm{Cr}$ and $\mathrm{Cd}$ are heavy metals of concern in the study area. Periodic evaluation of the heavy metal content of surface water in the study area is necessary in order to monitor deterioration in the quality of the water and also to recommend adequate treatment for the water before human consumption.
\end{abstract}

KEYWORDS: human health, heavy metals, rivers, treatment

\section{INTRODUCTION}

Environmental changes, worldwide, have intensely increased the overall environmental concentration of heavy metals (Lee et al., 2005). Rapid industrialization and urbanization have made heavy metal pollution a serious problem in many developing countries (Islam et al., 2015). Heavy metals are present in virtually every aspect of contemporary life, being abundant in air, soil and potable water (Chen et al., 2016). Heavy metals in the environment are caused by both natural and anthropogenic activities (Khan et al., 2008). Naturally occurring heavy metals are not harmful to humans and the environment because they are present in very small quantities (Sanayei et al., 2009). Heavy metal pollution in rivers and streams is largely caused by industrialization (Staley et al., 2015; Nguyen et al., 2016). The heavy metal content of surface water bodies is continually increasing thereby deteriorating water quality as a result of the disposal of urban wastes and untreated domestic and industrial in the surface water bodies (Venugopal et al., 2099).

River sediments are known to be the storage mechanisms of heavy metals, which eventually become the potential secondary source of metal pollution in water bodies (Yang and Wang, 2017). Metal deposits in streams could contribute to heavy metal pollution of the water body (Myangan et al., 2017). Different heavy metals are known that can impact human health and contribute to a variety of adverse health problems (Romero et al., 2001). Cadmium, Copper and Zinc, are among 10 toxic heavy metals of public health concern (World Health Organization, 2017). 
The world's population is increasing at an alarming rate, yet the amount of water available for human consumption remains the same (Bishnoi and Arora, 2007). Man's desire to survive despite all odds especially in developing countries has resulted in the consumption of river water without treatment. Heavy metal deposits in river tributaries may contribute to the heavy metal concentration in the main stream (Myangan et al., 2017) thereby endangering human and aquatic life. This study aims to assess the heavy metal content of some river tributaries in an urban settlement in Nigeria.

\section{METHODOLOGY}

\section{Case Study area}

This study was carried out in Shagari Federal Government housing estate popularly known as Shagari village. Shagari village is located in Akure. The geographical coordinates of Akure are $7^{\circ} 15^{\prime} 0^{\prime \prime}$ North and $5^{\circ} 12^{\prime} 0^{\prime \prime}$ East. Akure is a small commercial city and a central transportation spot that links major towns and cities like Owo, Ondo, Ado-Ekiti and Ilesha. The major river that flows through Akure is the Ala river. Ala river drains into Ogbese river which is located in the eastern part of the metropolis. Many small tributaries drain water to Ala river. Some of such tributaries are located in Shagari village. Some residents of Shagari village use water from these tributaries for domestic use.

\section{Sample collection}

Water samples were collected from five streams in Shagari village. The coordinates of the streams are presented in Table 1. The streams were located with respect to a datum point. Figure 1 shows the location of the sampling points. The water samples were collected in 1L capacity plastic bottles, prior to sampling, the sampling bottles and caps were rinsed three times with the water to be sampled. After collection, the samples were transported within 4 hours to the laboratory in order to preserve the integrity of the water.

Table 1: Coordinates of Stream Water sampling points

\begin{tabular}{|l|l|l|}
\hline STREAM & COORDINATE X & COORDINATE Y \\
\hline A & 806629.4677 & 742422.5077 \\
\hline B & 806782.6734 & 742418.4781 \\
\hline C & 806840.6102 & 742419.9823 \\
\hline D & 806945.9277 & 742415.7880 \\
\hline E & 807044.6689 & 742394.5168 \\
\hline
\end{tabular}




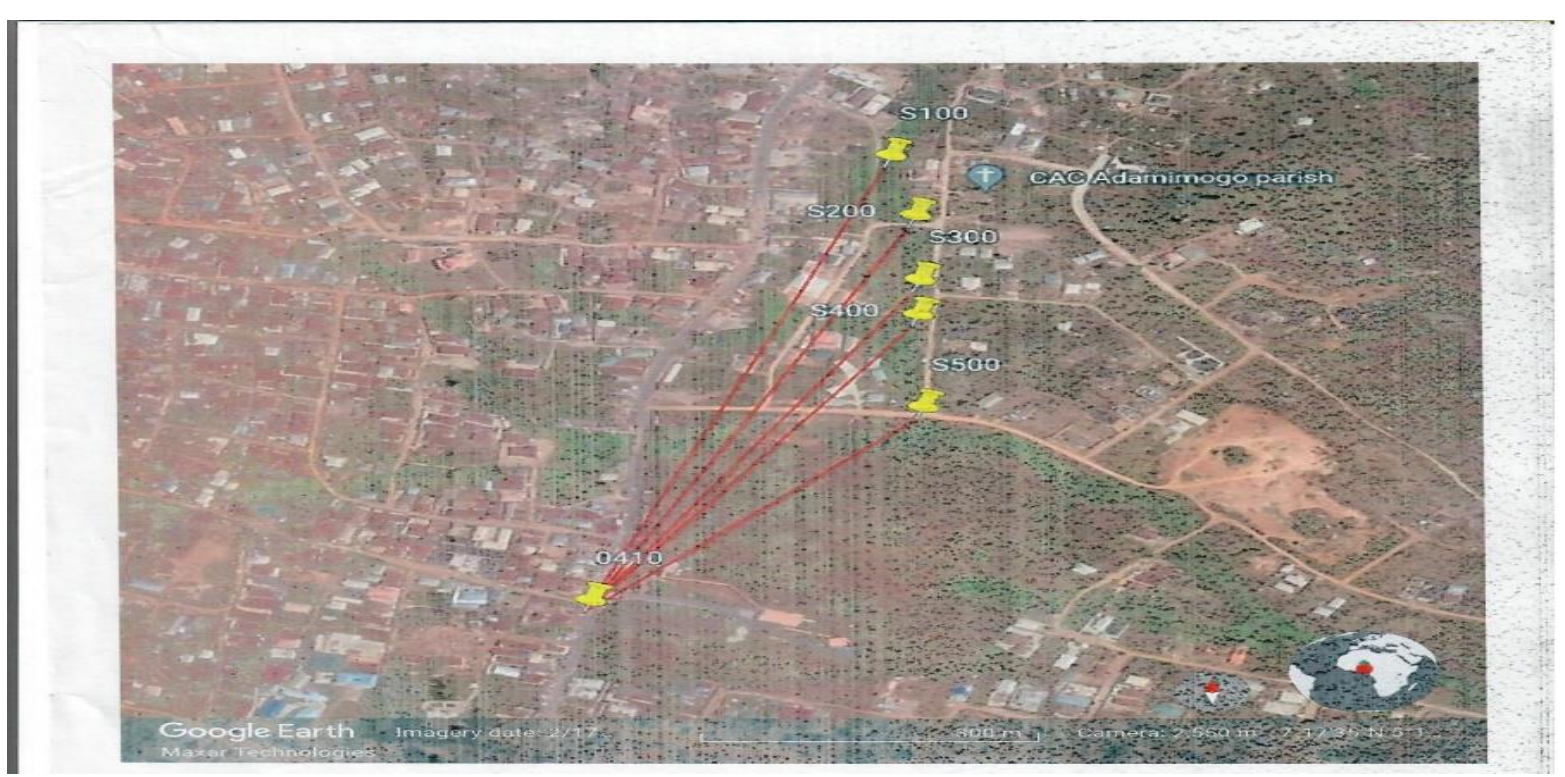

Figure1: Sampling points of the stream water

\section{Heavy metals Determination}

Four (4) heavy metals namely Iron (Fe), Chromium (Cr), Cadmium (Cd) and Manganese (Mn) were analyzed in the laboratory. The analysis were carried out in Sustainable Laboratory, Akure, Ondo State. The samples were stored briefly at $4{ }^{0} \mathrm{C}$ before analysis in order to minimize changes in the physicochemical characteristics of the heavy metals (Tuzen and Soylak, 2006). Atomic absorption spectrometry was used in the heavy metal analysis as described in APHA (2005).

\section{RESULTS AND DISCUSSIONS}

The results obtained from the heavy metals analysis were compared with WHO standard for potable water.

\section{Iron $(\mathrm{Fe})$}

The Fe content of the stream water samples collected is presented in Figure 2. From the results, it can be seen that all the stream water samples conformed to WHO Fe standard for potable water as they fell below the WHO maximum permissible limit of $0.3 \mathrm{mg} / \mathrm{L}$. 


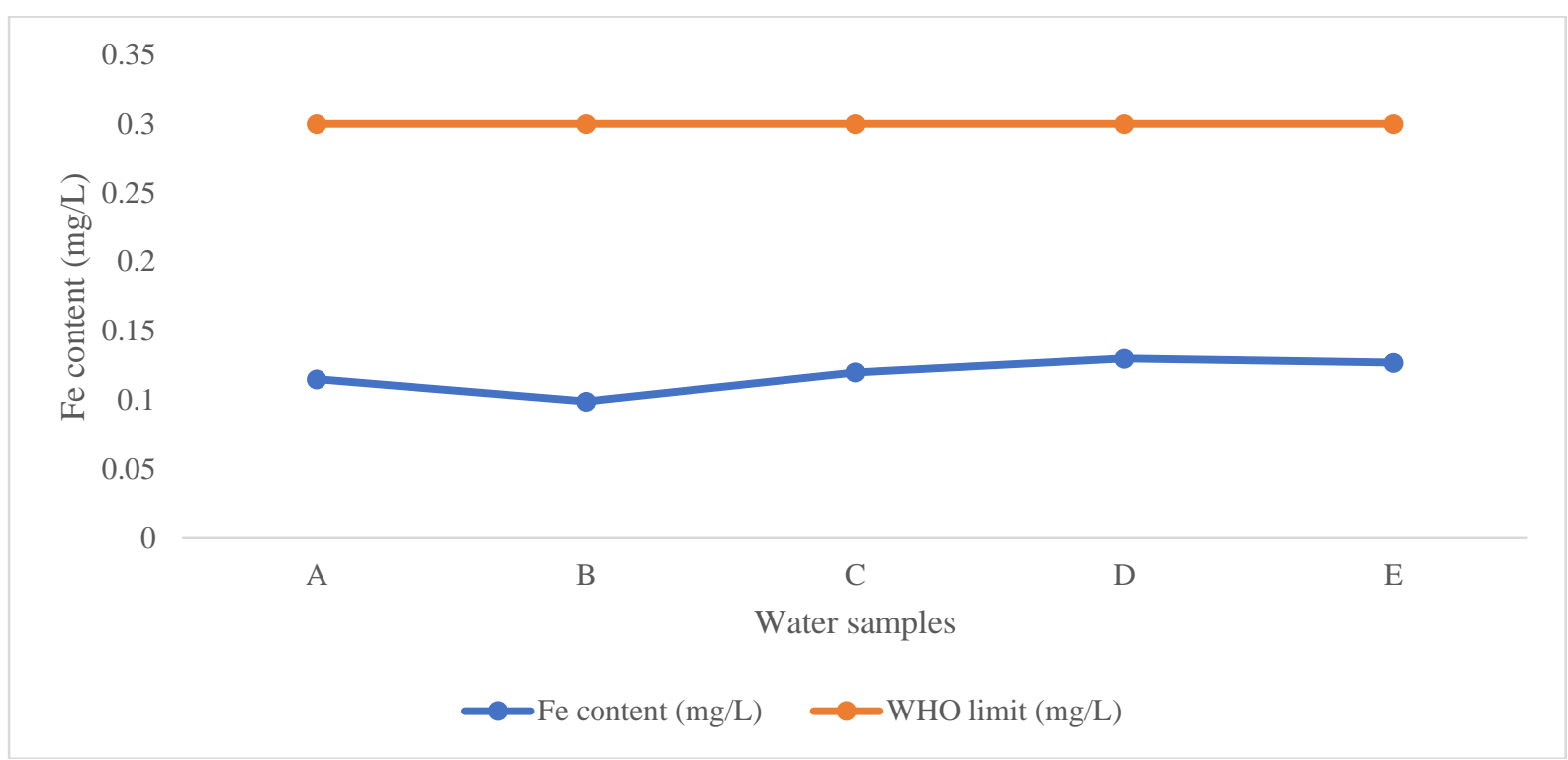

Figure 2: Fe concentration in stream water samples

\section{Chromium (Cr)}

The $\mathrm{Cr}$ value of stream water sample is presented in Figure 3. The results revealed that none of the stream water samples conformed to WHO $\mathrm{Cr}$ standard for potable water. Elevated quantities of $\mathrm{Cr}$ in potable water can cause nausea, gastrointestinal distress, kidney, lungs and liver damage as well as reproductive problems. $\mathrm{Cr}$ in water can be removed through reverse osmosis, distillation and use of activated carbon. High level of $\mathrm{Cr}$ in some of the water samples might have originated from urban and industrial wastes (Mohiuddin et al., 2012).

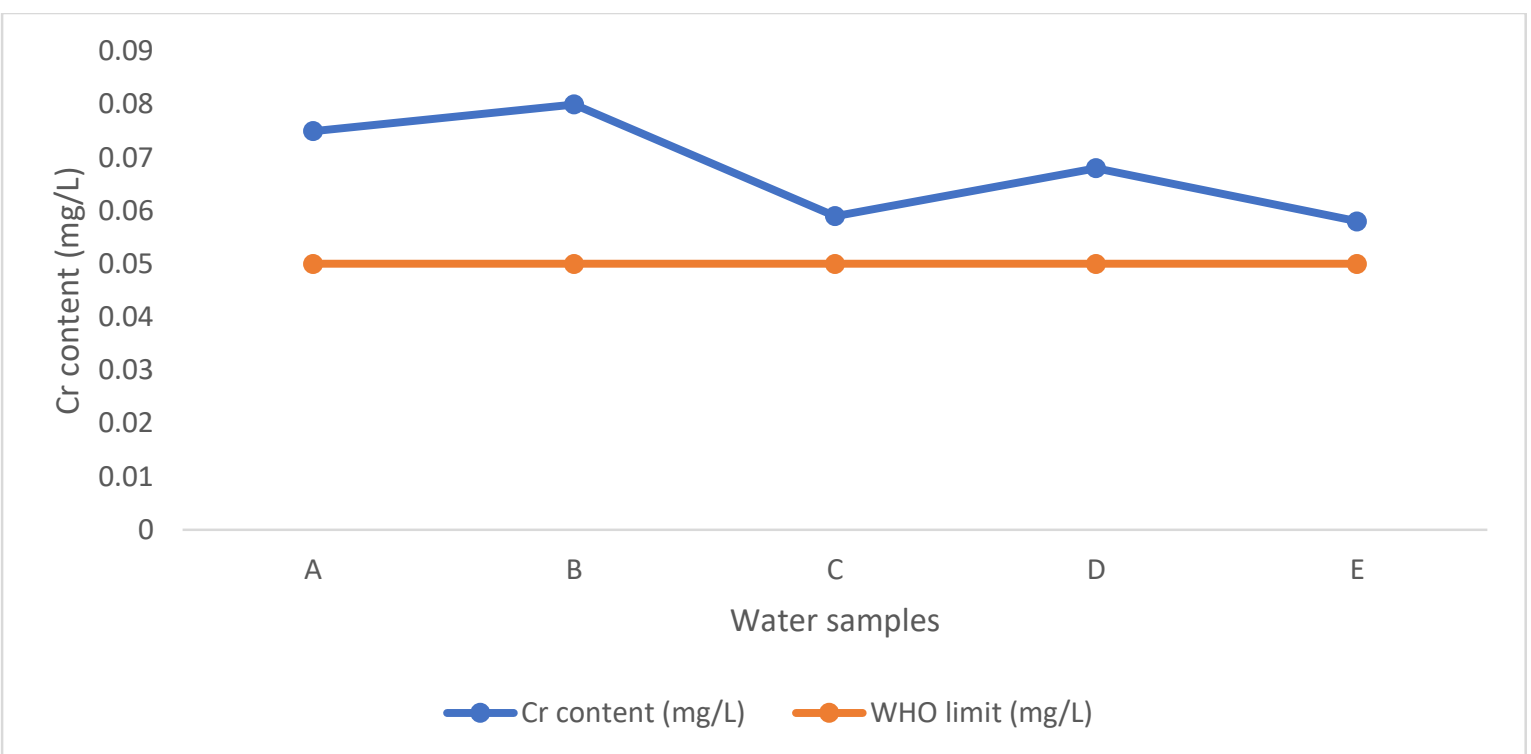

Figure 3: $\mathrm{Cr}$ concentration in stream water samples

\section{Cadmium (Cd)}

The $\mathrm{Cd}$ value of stream water sample is presented in Figure 4. The results revealed that sample, $\mathrm{A}, \mathrm{B}$ and $\mathrm{E}$ did not conform to WHO Cd standard for potable water. $\mathrm{Cd}$ is widely used in 
electroplating, plastics, paints and battery industries (Nassef et al., 2006). Sources of Cd contaminant in stream water include erosion of natural deposits, runoff from waste batteries and paints as well discharge from metal industries, hence, the main sources of $\mathrm{Cd}$ in water are industrial activities. Potential health effects include Kidney damage and treatment methods include reverse osmosis and distillation (Rajappa et al., 2010),

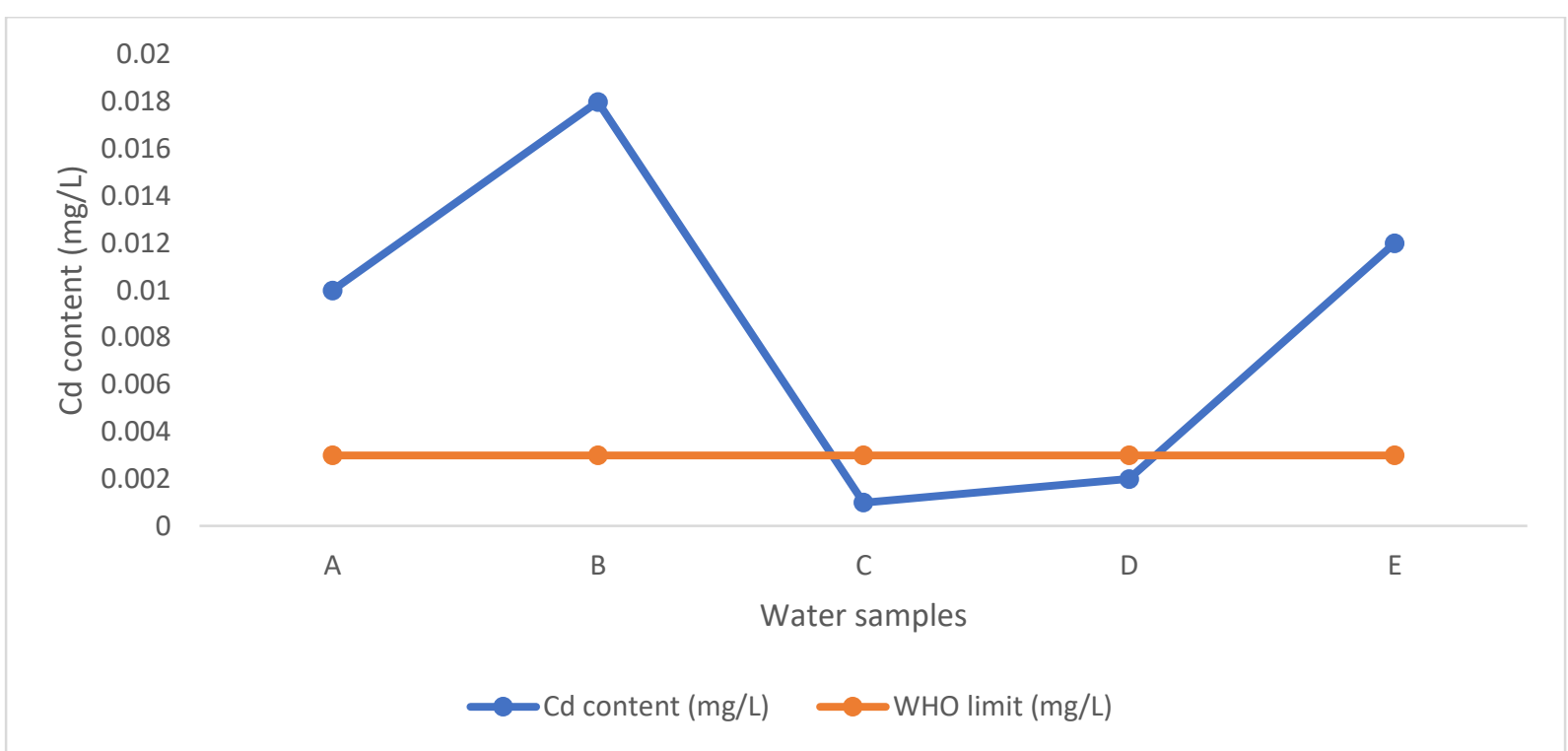

Figure 4: Cd concentration in stream water samples

\section{Manganese (Mn)}

The Mn value of stream water sample is presented in Figure 5. The results revealed that all the water samples analyzed fell within WHO maximum permissible limit for Mn in potable water which id $0.4 \mathrm{mg} / \mathrm{L}$. Mn is one of the most abundant elements in the earth's crust. Mn occurs naturally in many food substances, it is an essential element for humans. Exposure to elevated amounts of $\mathrm{Mn}$ in water can lead to irritability and neurological effects in humans.

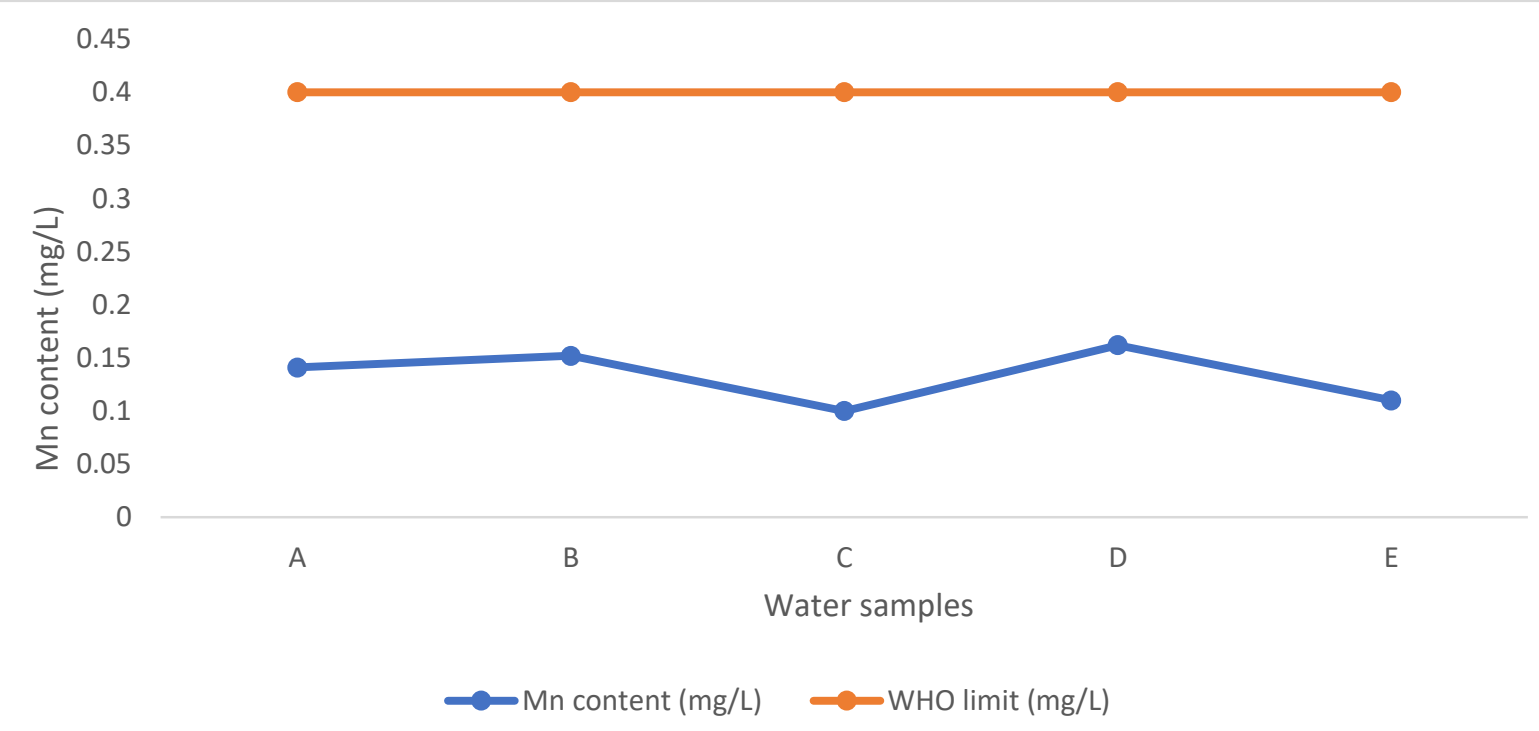

Figure 5: Mn concentration in stream water samples 


\section{CONCLUSION}

The study revealed that $\mathrm{Cr}$ and $\mathrm{Cd}$ are heavy metals of concern in stream waters in the study area. None of the water samples analyzed met WHO standard for $\mathrm{Cr}$ in potable water while $60 \%$ of the water samples analyzed did not conform to WHO standard for Cd in potable water. Periodic assessment of the heavy metal content of stream water in the study area is recommended in order to monitor any deterioration in the quality of the water. Also appropriate water treatment is recommended in order to make the water suitable for drinking purpose.

\section{REFERENCES}

American Public Health Association (APHA) 2005. Standard Methods for the Examination of Water and Wastewater. 20th Edn., American Public Health Association, Washington D.C., U.S.A.

Bishnoi, M and Arora, S. (2007). Potable ground water quality in some villages of Haryana, India: focus on fluoride. Journal of Environmental Biology, 28(2): 291-294.

Chen, C., Ju, Y., Chen, C. and Dong, C. (2016). Vertical profile, contamination assessment, and source apportionment of heavy metals in sediment cores of Kaohsiung Harbor, Taiwan. Chemosphere, 165: 67-79.

Islam, M.S., Ahmed, M.K., Raknuzzaman, M., Habibullah-Al-Mamun, M. and Islam, M.K.,

(2015). Heavy metal pollution in surface water and sediment: a preliminary assessment of an urban river in a developing country. Ecol. Indic. 48: 282-291

Khan, S., Cao, Q., Zheng, Y.M., Huang, Y.Z. and Zhu, Y.G., 2008. Health risks of heavy metals in contaminated soils and food crops irrigated with wastewater in Beijing, China. Environ. Pollut. 152: 686-692

Lee, M.; Cho, K.; Shah, A. P.; and Biswas, P. (2005). Nanostructured sorbents for capture of cadmium species in combustion environments. Environ. Sci. Technol. 39: 8481-8489

Mohiuddin, K.M., Otomo, K., Ogawa, Y., Shikazono, N. (2012). Seasonal and spatial distribution of trace elements in the water and sediments of the Tsurumi river in Japan. Environ. Monit. Assess. 184: 265-279.

Myangan, O., Kawahigashi, M., Oyuntsetseg, B. and Fujitake, N. (2017). Impact of land uses on heavy metal distribution in the Selenga River system in Mongolia. Environmental Earth Sciences, 76(9).

Nassef, M., Hannigan, R., EL Sayed, K.A and Tahawy, M.S.E. (2006). Determination of some heavy metals in the environment of Sadat industrial city. Proceeding of the 2nd Environmental Physics Conference, Cairo University, Egypt, pp. 145-152.

Nguyen, T., Zhang, W., Li, Z., Li, J., Ge, C., Liu, J., Bai, X., Feng, H. and Yu, L. (2016). Assessment of heavy metal pollution in Red River surface sediments, Vietnam. Marine Pollution Bulletin, 113:.513-519.

Rajappa, B., Manjappa, S and Puttaiah, E.T. 2010. Monitoring of heavy metal concentration in groundwater of Hakinaka Taluk, India. Contemporary Engineering Sciences, 3(4):183190.

Romero, F. M.; Armienta, M. A. and Carrillo-Chavez, A. Arsenic sorption by carbonate-rich aquifer material, a control on arsenic mobility at Zimapan, Mexico. J. Arch. Enviorn. Contam. Toxicol. 2004, 47, 1-13 
Sanayei, Y., Ismail, N and Talebi, S.M. (2009). Determination of heavy metals in Zayandeh rood, Isfahan-Iran. World Applied Sciences Journal, 6(9):1209-1214.

Staley, C., Johnson, D., Gould, T., Wang, P., Phillips, J., Cotner, J. and Sadowsky, M. (2015). Frequencies of heavy metal resistance are associated with land cover type in the Upper Mississippi River. Science of The Total Environment,511, pp.461-468.

Tuzen, M and Soylak, M. (2006). Evaluation of metal levels of drinking waters from the Tokat black sea region of Turkey. Polish Journal of Environmental Study, 15(6):915-919.

Venugopal, T., Giridharan, L., Jayaprakash, M. and Velmurugan, P.M. (2009). A comprehensive geochemical evaluation of the water quality of River Adyar India. Bull. Environ. Contam. Toxicol. 82, 211-217.

World Health Organization. (2017). World Health Organization. [online] Available at: www.who.int/entity/ifcs/documents/forums/forum5/8inf_rev1_en.pdf - 86k - 997k [Accessed 22 ${ }^{\text {nd }}$ November, 2021]

Yang, X. and Wang, Z. L. (2017). Distribution of dissolved, suspended, and sedimentary heavy metals along a salinized river continuum. Journal of Coastal Research, 33(5): 11891195 